\title{
Los programas de vigilancia médica ocupacional en los centros de trabajo.
}

Actualmente, los riesgos a la salud de los trabajadores derivados de su ambiente de trabajo presentan desafíos para cualquier programa de control de pérdidas en todas las empresas cualquiera sea la actividad que realice. Las recientes investigaciones sobre antiguos riesgos, los nuevos riesgos identificados por la tecnología de información, el descubrimiento e incorporación de nuevos agentes químicos a las industrias, etc., determinan la necesidad de un mayor esfuerzo por comprender las diversas interacciones que pueden afectar al recurso más importante y vital de toda empresa: sus trabajadores (1). Sin embargo, sólo en los últimos tiempos, la prevención laboral es foco de una preocupación real y constante. Por ello, es imprescindible prestar una especial atención a los programas de vigilancia médica ocupacional de los trabajadores, una variable compleja con dos dimensiones: una humana y social y otra económica. Cuando un trabajador se enferma o accidenta, influye negativamente sobre la calidad del trabajo y en la economía de la organización en general; el costo se eleva, porque se debe pagar un salario a quien lo sustituye; y un subsidio al primero (2). Con frecuencia, también se producen afectaciones al proceso de producción, si se emplea un trabajador con menos experiencia y destreza, se originarán interrupciones que perjudican el resto del proceso productivo o de servicio. Los programas de vigilancia médica ocupacional en los centros laborales se constituyen en los procedimientos y prácticas médicas caracterizados por la identificación de los problemas de la salud relacionados con las tareas desarrolladas por los trabajadores en sus puestos de trabajo, el análisis de las causas de los mismos y la elaboración de las recomendaciones para el manejo y rehabilitación, en forma integral y multidisciplinaria. Se entiende por vigilancia, al análisis, interpretación y difusión sistemática de datos colectados, generalmente, por medio de métodos que se distinguen por ser prácticos, uniformes y rápidos, más que por su exactitud o totalidad, y que sirven para observar las tendencias en tiempo, lugar y persona; con ellos, pueden observarse o anticiparse cambios, que requieren acciones oportunas, como la investigación o la aplicación de medidas de prevención y control (3).

El objetivo de toda vigilancia médica ocupacional es la protección de la salud de los trabajadores a través de evaluaciones médicas periódicas. Esto nos permitirá comprobar si los programas de control preventivo de las empresas están cumpliendo con la protección de los trabajadores (4). Además, es importante enfatizar la verdadera función de toda vigilancia médica ocupacional, dado que no debe convertirse en una herramienta de fiscalización del empleador, a tener en cuenta para diferenciar al médico ocupacional o del trabajo con el médico de empresa. La verdadera vigilancia médica esta dirigida a evaluar la capacidad funcional del trabajador y no a valorar el menoscabo o limitación física del mismo. Otra situación que ocurre con los programas de vigilancia médica ocupacional es el atribuirle una función no ocupacional como la identificación de trabajadores alcohólicos, con adicciones, promoción de la salud, programa de 
vacunaciones, etc. Un programa de vigilancia médica ocupacional debe iniciarse tras la sensibilización de los empleados y los empleadores, informándose los beneficios hacia la salud individual y corporativa, además del cumplimiento de lo requerimientos legales. La comprensión y profundización del mismo determinará la persistencia y ventajas del programa.

A pesar del desarrollo farmacológico y tecnológico de las ciencias médicas, que han permitido detectar algunas enfermedades en sus inicios, curarlas y controlarlas, son muchas las enfermedades ocupacionales serias que nosotros enfrentamos que son irreversibles no siempre prevenibles. Esto debido a la característica de las enfermedades ocupacionales que se desarrollan en un tiempo relativamente prolongado por un efecto continuo y acumulativo de las noxas ocupacionales muchas veces imperceptibles a los ojos inexpertos. Por ello, se agrega la habilidad de identificar peligros y analizar los riesgos hacia la salud en los puestos de trabajo con el objetivo de eliminarlos o minimizarlos, sobretodo ante la exposición a agentes químicos, físicos y biológicos. Sin embargo, este último debe ser desarrollado a través del equipo multidisciplinario de la Salud Ocupacional, conformado por el médico ocupacional, el enfermero de empresa, el higienista, el ingeniero de seguridad, el especialista de ergonomía, el psicólogo laboral, etc. Actualmente en diversos países, incluido el Perú, no se puede contar con el equipo completo, por la carencia de entidades formadoras de estos profesionales o por lo limitado del número de estos profesionales (5).

Los exámenes médicos dentro de un programa de vigilancia de la salud ocupacional de los trabajadores deberían ser realizados por médicos especialistas o médicos generales con conocimientos básicos bajo la supervisión de dicho médico. Las empresas en nuestro medio están facultadas para tener su propio médico ocupacional o pueden contratar médicos externos. El empleador debe asumir los costos de estas evaluaciones según las recomendaciones de la Organización Internacional para el Trabajo (OIT). Nuestro país ha oficializado esta recomendación $(5,6,7)$.

No todos los médicos están calificados para evaluar enfermedades derivadas del trabajo. No basta la habilidad del médico general en su ejecución, pues el conocer las tareas de las diversas ocupaciones y oficios es una necesidad a la hora de evaluar la salud del trabajador (1). La evaluación médica no debe ser confundida con el llenado solo de la ficha médica ocupacional, sino por la habilidad de identificar efectos dañinos hacia la salud derivados del ambiente laboral, lo cual se adquiere con un fundamento teórico pero con una proporción importante de práctica en el centro laboral.

Los resultados de los reconocimientos médicos, al igual que todo acto médico, tienen la característica de ser confidenciales $(8,9)$, y la comunicación de los mismos deben hacerse exclusivamente en términos de aptitud para las tareas de su puesto de trabajo. En los casos de detección de enfermedades ocupacionales o de sospecha de los mismos debe aplicarse los protocolos establecidos para el monitoreo y análisis de los factores de riesgo laboral así como la respuesta individual que la produjo. (5). Además se debe involucrar a las otras especialidades médicas para su confirmación y/o manejo.

En conclusión, creemos necesario difundir las características de la Medicina Ocupacional y del Medio Ambiente, que resurge no solo como una especialidad médica sino como una necesidad sociolaboral estratégica al momento de evaluar la salud pública de nuestra población trabajadora y de la comunidad.

\section{Raúl Gomero Cuadra ${ }^{1}$, Juan Palomino Baldeon², Carlos Llap Yesan ${ }^{3}$.}

${ }^{1}$ Médico especialista en Medicina Ocupacional y del Medio Ambiente egresado de la Universidad Peruana Cayetano Heredia

${ }^{2}$ Residente de Medicina Ocupacional y del Medio Ambiente de la Universidad Peruana Cayetano Heredia ${ }^{3}$ Coordinador del Programa de Medicina Ocupacional y del Medio Ambiente de la Universidad Peruana Cayetano

\section{REFERENCIAS BIBLIOGRÁFICAS}

1. LaDou J. La práctica de la medicina del trabajo. En: LaDou J. Medicina laboral y ambiental. Segunda edición. Mexico DF: El Manual Moderno;1999. p. 3-7.

2. Keyes C, Grzywacz J. Health as a complete state: The added value in work performance and healthcare costs. JOEM 2005; 47 (5): 523-531.

3. OPS. Módulos de principios de la epidemiología para el control de las enfermedades. Unidad 4. Vigilancia en salud pública. 2nd edition. Washington DC: OPS; 2002. p. 4-18. 
4. García M. La vigilancia de la salud de los trabajadores. Mapfre Seguridad 1998; 69(1):83-87.

5. Rescalvo F. Manual de prevención de riesgos laborales.Madrid: IBERMUTUAMUR; 1998. p. 5457.

6. Gil F. Tratado de Medicina del Trabajo. Barcelona: Masson; 2005. p. 851-892.
7. Ministerio de Energía y Minas del Perú. Reglamento de Seguridad e Higiene Minera DS N 046-2001. Lima: Ministerio de Energía y Minas del Perú; 2001.

8. Organización Internacional del Trabajo -OIT. Convenio $\mathrm{N}^{\circ} 161$ sobre servicios de salud en el trabajo. Ginebra:OIT; 1985.

9. Rothstein M. A proposed revision of the ACOEM Code of Ethics. JOEM 1997;39(7): 616-622. 